\title{
ESTUDO DE USUÁRIOS NO SERVIÇO DE REFERÊNCIA E INFORMAÇÃO DA BIBLIOTECA PÚBLICA BENEDITO LEITE: relato de experiência vivenciada na disciplina Referência no curso de Biblioteconomia da Universidade Federal do Maranhão
}

MARCIA CORDEIRO COSTA*

\begin{abstract}
RESUMO
Trata de uma experiência vivenciada na condução da disciplina Referência, ministrada no curso de graduação em Biblioteconomia da Universidade Federal do Maranhão, no primeiro semestre letivo de 2017. Apresenta a importância da aprendizagem significativa na formação do acadêmico. Constata que a experiência de pesquisa contribui para o aprendizado significativo dos acadêmicos de Biblioteconomia sobre a temática do estudo de usuário no SRI.
\end{abstract}

PALAVRAS-CHAVE: Referência; Estudo de Usuários; Ensino em Biblioteconomia; Aprendizagem significativa.

\begin{abstract}
It is an experience lived in the conduction of the subject Reference, taught in the undergraduate course in Librarianship of the Federal University of Maranhão, in the first semester of 2017. It presents the importance of meaningful learning in the academic formation. It notes that the research experience contributed to the significant learning of the Librarianship scholars on the subject of the SRI user study
\end{abstract}

KEYWORDS: Reference; Study of Users; Teaching in Librarianship; Sgnificative Learning.

\section{INTRODUÇÃO}

O Serviço de Referência e Informação (SRI) é considerado por alguns autores, o coração da unidade de informação, "[...] no qual é bombeado todo sangue informacional, o qual prévia e

\footnotetext{
* Professora Assistente - A, do Departamento de Biblioteconomia da Universidade Federal do Maranhão.
} 
tecnicamente tratado irá prover aos usuários pontos diversos de acesso à informação" (MACEDO; MODESTO, 1999, p. 41). Logo, as bibliotecas ou unidades de informação, como são designadas, devem buscar constantemente a promoção da qualidade, o que pode ser traduzido pela procura da melhoria contínua. Assim como as demais organizações existentes, essas entidades necessitam avaliar a eficiência e eficácia de seus produtos e prestação de serviços, a fim de comprovar acertos, detectar falhas e propor soluções para problemas.

O usuário de uma Unidade Informacional tem características próprias e necessidade de informação diferenciada. Desse modo, se faz necessário conhecê-lo para saber o que ele espera com o atendimento informacional a ele dispensado e, o quanto essa disseminação de informação contribui em suas necessidades e expectativas. Assim, o bibliotecário deverá estar preparado para lidar com o sujeito usuário da informação, que é a razão de ser de sua profissão, em toda sua complexidade e subjetividade humana e numa perspectiva multidisciplinar (NASCIMENTO, 2011).

$O$ advento de um novo paradigma, que sucede o que estava centrado nos acervos, estabeleceu o foco nas necessidades dos usuários e das comunidades, e, tendo em vista essa nova visão, o usuário passa a ser agente ativo do processo de disseminação informacional. Para que isso ocorra, o bibliotecário gestor no Serviço de Referência e Informação deve ter domínio da sua profissão, e o desempenho de múltiplas funções (busca e recuperação da informação; investigação bibliográfica; atenção a diversos tipos de usuários; interpretação das questões/problemas do usuário), e visão ampliada para detectar os sinais do usuário nesse ambiente, tornando-se sensível ao usuário no sentido de conhecer a seu público e compreender os motivos que os levam a frequentar esse espaço.

Nesse sentido evidencia-se, sobretudo, a necessidade de um eficaz estudo de usuário para a identificação de suas reais necessidades. (FIGUEIREDO, 1994, p. 10, grifo nosso) declara que: "[...] no que diz respeito aos estudos dos usuários [...] guiam a política de seleção de uma biblioteca [...] apontam as diretrizes para o serviço de referência e de disseminação da informação, sob todas as formas."

Inebriada dessas questões, e na condução da disciplina Referência, propôs-se aos estudantes inscritos na disciplina do semestre 2017.1 a elaboração em equipes de pesquisas com usuários, as quais representariam uma das atividades avaliativas da disciplina, compondo um requisito para conclusão da mesma. 
Elegeu-se como campo de investigação a Biblioteca Pública Benedito Leite dada à importância dos seus serviços meio e fim voltados para a sociedade maranhense, sendo esta uma referência em trabalhos de promoção da leitura, espaço de pesquisa, acessibilidade, e em preservação de acervos, hoje, através de um trabalho sério de democratização do acesso à Informação, tendo como lema, a universalidade, tem procurado atingir seu objetivo maior de transformar-se em uma biblioteca para todos.

Pensando na vertente de tornar a aprendizagem da disciplina Referência significativa, adotou-se a Teoria de Ausubel. Segundo (PELIZZARI, 2002), na década de 1960, David Paul Ausubel, psicólogo norte-americano, formulou a Teoria da Aprendizagem Significativa, diferenciando-a da aprendizagem mecânica, fornecendo orientações e instruções úteis ao ato de ensinar e à compreensão da aprendizagem, a partir de uma nova visão.

Nessa compreensão, acredita-se que o desenvolvimento da prática proposta em sala de aula é relevante para proporcionar aos discentes amplos conhecimentos sobre o Serviço de Referência e Informação (SRI) e a adoção dos estudos de usuários por meio das informações teóricas e da prática exteriorizados, de forma que isso possa exercer influência sobre tais futuros bibliotecários, favorecendo a promoção de benefícios ou mudanças positivas para a gestão de pessoas, jornada importante que irão trilhar em suas atividades profissionais em Bibliotecas. A presente proposta de estudo de usuário teve como objetivo:

- Identificar o perfil do usuário, seus hábitos, suas preferências, e comportamento de busca e uso da informação;

- Averiguar as necessidades informacionais dos usuários a partir do SRI;

- Analisar a satisfação dos usuários da biblioteca Pública Benedito Leite;

- Descrever os produtos e serviços oferecidos pela BPBL;

- Verificar a mediação da informação junto ao usuário no SRI.

Logo, o intuito de conceder aos alunos a oportunidade de desenvolver essa prática visou promover uma interação entre todos os discentes e facilitar a organização de informações em aprendizado, ainda no período de formação, ao campo onde ele poderá atuar após a conclusão de seu curso. Com orientação técnica e mediadora o aluno tem a possibilidade de enriquecer seus estudos e conhecimentos, até então restritos apenas ao ambiente acadêmico, podendo assim exercer na prática todo o aprendizado 
adquirido ao longo de suas leituras e pesquisas realizadas durante as aulas.

\section{DESCRIÇÃO DAS ETAPAS REALIZADAS NA PESQUISA}

Com a finalidade de fornecer subsídios teóricos e conhecimentos sobre a realidade dos $\mathrm{SRI}$ e os estudos de usuários, além da abordagem teórica, discussões e processos avaliativos comuns da disciplina, propôs-se como requisito à conclusão da disciplina Referência a elaboração do artigo cientifico. Os estudantes a partir da orientação em sala de aula elaboraram o projeto e os instrumentos, para efetuar a coleta dos dados e posteriormente a elaboração do artigo. As atividades in loco foram realizadas sob minha supervisão nas quartas-feiras nos horários da disciplina (4horários), contudo propôs-se que a turma deveria dividir-se em quatro equipes contemplando os quatro setores da Biblioteca Pública como descrito no quadro abaixo.

QUADRO 1 - Equipes de pesquisa sobre estudo de usuários no SRI da Biblioteca Pública Benedito Leite

\begin{tabular}{|c|c|}
\hline EQUIPES & ESTUDO DE USUÁRIOS (SRI) \\
\hline 1 & SETOR DO ACERVO RARO \\
\hline 2 & BIBLIOTECA INFANTIL E JUVENIL VIRIATO CORRÊA \\
\hline 3 & ALUNOS DO ENSINO MÉDIO DAS ESCOLAS PÚBLICAS \\
\hline 4 & SEÇÃO DE INFORMAÇÃO BRAILLE \\
\hline
\end{tabular}

FONTE: Da autora

Os setores acima citados da BPBL para aplicação foram definidos por sorteio, mas a forma de abordagem das investigações foi definida a partir do levantamento bibliográfico sobre o tema. Após a realização da pesquisa, ao final da disciplina, os alunos disseminaram os conhecimentos adquiridos com a visualização de diferentes realidades por meio do seminário. Antes do início de cada apresentação, foi realizado um sorteio onde outra equipe foi selecionada para avaliação do trabalho da equipe que iniciaria. Durante o período da apresentação oral, os membros do grupo avaliador estavam de posse do trabalho impresso.

Acredita-se que a ação de avaliação dos trabalhos possibilita um aprendizado ativo no momento em que são ouvidas recomendações, potencialidades e fragilidades da apresentação oral e escrita e, não somente de forma passiva efetivada pela 
avaliação da professora quando da leitura das pesquisas realizadas. Ao professor, cabe o papel de orientador e facilitador da aprendizagem, conforme lembra (MASETTO, 1997): Para que a aprendizagem realmente aconteça, ela precisa ser significativa para o aluno, envolvendo-o como pessoa. Trata-se de um processo que permita ao aluno relacionar o que está aprendendo com os conhecimentos e experiências que já possui; que o incentive a perguntar a apresentar questões que o envolvam. Como destaca (RUÉ, 2009, p. 10) "[...] a configuração das novas sociedades e da própria noção de democracia e sua progressiva ampliação requerem cidadãos capazes de refletir sobre si mesmos".

É importante destacar que em pleno século XXI, estamos diante de uma sociedade pós-industrial, denominada sociedade da informação, sociedade do conhecimento ou sociedade em rede. A mudança promovida pelo impacto tecnológico impõe a esses dois personagens (bibliotecário e usuário) grandes desafios. $O$ processo de referência, assim como os demais segmentos da Biblioteconomia, passou por mudanças em suas práticas, incentivadas pelo avanço tecnológico, a internet e junto a eles os sistemas on-line. O profissional da informação deve ser, sobretudo, um "[...] refinador humano da informação com valor agregado para serviços específicos" (LUCAS, 1996, p. 69).

Entretanto, apesar do crescente avanço tecnológico, as principais atribuições do bibliotecário não mudaram, pois seu trabalho continua sendo o de intermediário entre a informação e o usuário. $\mathrm{Na}$ fala de (GROGAN, 2001, p. 60) "[...] os avanços da tecnologia em pouco alteraram a receita", ou seja, mesmo com todo aparato tecnológico o bibliotecário facilita o acesso à informação pelo usuário. (SILVA e CUNHA, 2002, p. 81) corroboram "[...] o bibliotecário é em sua essência um mediador, um comunicador, alguém que põe em contato informações com pessoas, pessoas com informações".

Hoje, nessa nova sociedade da informação, o bibliotecário tem que interagir entender e buscar meios de acessar e dar acesso à informação de acordo com o usuário que a unidade possui. Desta forma, poderá o profissional da informação realizar um atendimento satisfatório a esses indivíduos nos seus diversos interesses, sejam eles culturais educacionais ou profissionais, contribuindo para sua inclusão social.

Para que isso ocorra, o bibliotecário gestor no SRI deve ter domínio da sua profissão, e o desempenho de múltiplas funções (busca e recuperação da informação; investigação bibliográfica; atenção a 
diversos tipos de usuários; interpretação das questões/problemas do usuário), e visão ampliada para detectar os sinais do usuário nesse ambiente, tornando-se sensível ao usuário no sentido de conhecer a seu público e compreender os motivos que os levam a frequentar esse espaço. É imperativo que ele se aperfeiçoe permanentemente, potencializando suas habilidades para atender aos usuários de forma eficiente, essa atitude. "[...] influenciará diretamente a vida de todas as pessoas e irá requerer competências de cunho educativo, intelectual, social e tecnológico". (SILVA; CUNHA, 2002, p. 82).

Nesse caso, retomamos aqui a afirmativa que a experiência, aliada às habilidades humana e técnica, é o cerne para a qualidade desse serviço nas Bibliotecas. Muitas dessas atividades se atribuem à eficiência de um SRI, por isso (RANGANATHAN, 2009, p. 287) o definiu como "[...] o motivo fundamental e a culminância de todas as práticas biblioteconômicas.". Manter uma atitude amigável e aberta para com o usuário, a fim de descobrir qual a real necessidade de informação. Conhecer as fontes de informação e as técnicas de manuseio das obras. Realizar busca cuidadosa e sistemática da literatura com a seleção correta da resposta adequada; incluindo aqui o tempo consumido para isso. Conhecer fontes de informação fora da biblioteca, conhecimento que deve obter por treinamento em serviço. (FIGUEIREDO, 1994, p. 51). Esse é o caso, por exemplo, da compreensão do Serviço de Referência e Informação nas abordagens de (GROGAN, 2001), (ALMEIDA JÚNIOR, 2009) e (MACEDO, 1990). Para um aluno que percebe a realidade social, notará rapidamente que as questões envolvidas superam as fases ou o conjunto de passos de um processo de atendimento ao usuário, que não é um sujeito ahistórico. A saída teórica e prática foram pensar e fazer com que os discentes reflitam a respeito que, os profissionais da informação são mediadores, e como tais, devem reconhecer seu papel histórico-social e a necessária interferência que consiste na base que distingue um mediador de um profissional tradicional (ALMEIDA JÚNIOR, 2009)

\section{CONCLUSÃO}

Em síntese, proposições como essas são oportunidades de exercitar o aprendizado adquirido em sala durante as aulas, que possibilita, ainda, que o acadêmico tenha um conhecimento mais aprofundado acerca da disciplina Referência.

Nesse sentido, na avaliação geral sobre as atividades desenvolvidas a partir dessa pesquisa na disciplina Referência, constatou-se que não haverá responsabilidade nem comprometimento 
com o acesso à informação se os profissionais mediadores não conhecerem a realidade social. Para conseguir que os futuros mediadores possam ser responsáveis e partícipes do acesso irrestrito à informação, sugiro, que mais disciplinas dos cursos de Biblioteconomia integrem a discussão do papel social da profissão, atrelado ao conhecimento técnico exigido.

Logo, com toda a experiência adquirida durante a realização dessa atividade com os alunos, acreditamos ter contribuído de alguma forma, para o desenvolvimento da instituição concedente, assim como para a melhoria dos serviços desempenhados pela mesma, e a aquisição de conhecimentos e suporte informacional para o mercado de trabalho.

\section{REFERÊNCIAS}

ALMEIDA JÚNIOR, O. F. Mediação da informação e múltiplas linguagens. Tendências da Pesquisa Brasileira em Ciência da Informação, v. 2, n. 1, p. 89-103, jan./dez. 2009. Disponível em: <http://inseer.ibict.br/ancib/index.php/tpbci/article/view/17/39>. Acesso em: 20jul. 2017.

AUSUBEL, D. P. A aprendizagem significativa: a teoria de David Ausubel. São Paulo: Morais, 1982.

FIGUEIREDO, Nice Menezes de. Estudos de uso e usuários da informação. Brasília: IBICT, 1994.

GROGAN, Denis. A prática do serviço de referência. Tradução de Antonio Agenor Briquet de Lemos. Brasília: Briquet de Lemos/Livros, 2001.

LUCAS, C. R. A organização do conhecimento e tecnologias da informação: oráculos humanos e inteligência artificial. In:__. Organização do conhecimento e sistemas de classificação. Brasília: MCT/CNP IBICT, 1996. p. 69-73.

MACEDO, Neusa Dias de ; MODESTO, Fernando. Equivalências: do Serviço de Referência convencional a novos ambientes de redes digitais em bibliotecas. Revista Brasileira de Biblioteconomia e Documentação: Nova Série, São Paulo, v. 1, n. 1, p. 38-54, 1999.

MACEDO, Neusa Dias de. Princípios e reflexões sobre o serviço de referência e informação. Revista Brasileira de Biblioteconomia e Documentação, São Paulo, v. 23, n. 1-4, p. 9-37, jan./dez. 1990.

MASETTO, M.T. Didática: a aula como centro. São Paulo: FTD, 1997.

NASCIMENTO, M. J. de. Usuário da informação como produção científica e disciplina curricular: origem dos estudos e o ensino no Brasil. Revista Digital de Biblioteconomia \& Ciência da Informação, Campinas, v. 8, n. 2, p. 41-71, jan./jun. 2011. 
RANGANATHAN, S. R. As cinco leis da biblioteconomia. Tradução de Tarcisio Zandonade. Brasília, DF: Briquet de Lemos/Livros, 2009.

RUÉ, J. Aprender com autonomia no ensino superior. In: ARAUJO, U. F.; SASTRE, G. Aprendizagem baseada em problemas. São Paulo: Summus editorial, 2009.

SILVA, Edna Lúcia da; CUNHA, Miriam Vieira da. A formação profissional no século XXI: desafios e dilemas. Ciência da Informação. Brasília, v. 31, n. 3, p. 77-82, set./dez. 2002. Disponível em: <http://www.scielo.br/pdf/ci/v31n3/a08v31n3.pdf>. Acesso em: 16 de mar. 2017. 